\title{
Eukaryotic catecholamine hormones influence the chemotactic control of Vibrio campbellii by binding to the coupling protein $\mathrm{CheW}$
}

Angela Weigert Muñoz ${ }^{a}$, Elisabeth Hoyer ${ }^{b}$, Kilian Schumacher ${ }^{b}$, Marianne Grognot ${ }^{c}$, Katja M. Taute ${ }^{c, 1}$, Stephan M. Hacker ${ }^{d, 2}$, Stephan A. Sieber ${ }^{\mathrm{a}, \mathrm{e}, 3}$, Kirsten Jung ${ }^{\mathrm{b}, 3}$

${ }^{a}$ Center for Functional Protein Assemblies, Technical University of Munich, 85748 Garching, Germany; bepartment of Biology I, Microbiology, Ludwig-Maximilians-University München, 82152 Martinsried, Germany, 'Rowland Institute, Harvard University, Cambridge, MA 02142, USA; dDepartment of Chemistry, Technical University of Munich, 85748 Garching, Germany; eHelmholtz Institute for Pharmaceutical Research Saarland, Helmholtz Center for Infection Research, 66123 Saarbrücken, Germany. Present address: ${ }^{1}$ Department of Biology I, Microbiology, Ludwig-Maximilians-University München, 82152 Martinsried, Germany; 'Leiden Institute of Chemistry, Leiden University, 2333 CC Leiden, Netherlands. ${ }^{3}$ Corresponding authors: jung@Imu.de; stephan.sieber@tum.de

\begin{abstract}
In addition to their well-known role as stress-associated catecholamine hormones in animals and humans, epinephrine (EPI) and norepinephrine (NE) act as interkingdom signals between eukaryotic hosts and bacteria. However, the molecular basis of their effects on bacteria is not well understood. In initial phenotypic studies utilizing Vibrio campbellii as a model organism, we characterized the bipartite mode of action of catecholamines, which consists of promotion of growth under iron limitation, and enhanced colony expansion on soft agar. In order to identify the molecular targets of the hormones, we designed and synthesized tailored probes for chemical proteomic studies. As the catechol group in EPI and NE acts as iron chelator and is prone to form a reactive quinone moiety, we devised a photoprobe based on the adrenergic agonist phenylephrine (PE), which solely influenced colony expansion. Using this probe, we identified CheW, located at the core of the chemotaxis signaling network, as a major target. In vitro studies confirmed that EPI, NE, PE, as well as labetalol, a clinically applied antagonist, bind to purified CheW with affinity constants in the sub-micromolar range. In line with these findings, exposure of $V$. campbellii to these adrenergic agonists affects the chemotactic control of the bacterium. This study highlights a previously unknown effect of eukaryotic signaling molecules on bacterial motility.
\end{abstract}

\section{Introduction}

Catecholamine hormones are widespread signaling molecules present in animals and humans, where they act as neurotransmitters and stress hormones. They include epinephrine (EPI), norepinephrine (NE), and dopamine, which all bear a characteristic catechol motif and a sidechain amine. It is well known that stress of the mammalian host increases its susceptibility to bacterial infections, and EPI and NE, for example, stimulate growth of the enterobacteria Salmonella enterica serovar Typhimurium, Escherichia coli, and Vibrio cholerae in serum-based media (1-4). In addition, EPI and NE affect biofilm formation, siderophore production, invasion of epithelial cells, and the expression of virulence factors (5-8). It is thus assumed that some bacteria use these hormones as cues to recognize the eukaryotic host environment and to occupy a niche in it (9). In eukaryotes, catecholamines bind to $\mathrm{G}$ protein-coupled receptors. The observation that certain antagonists of the human receptors also antagonize adrenergic effects in bacteria corroborates the hypothesis that receptors with a similar specificity may have evolved in prokaryotes. Indeed, binding of NE and EPI to the two-component system histidine kinases QseC and QseE was reported in enterohemorrhagic Escherichia coli O157:H7 (10, 11). However, not all adrenergic responses depend on QseC and/or QseE, as mutants lacking the corresponding homologous genes in Salmonella and $V$. cholerae were still responsive to catecholamines $(4,7,12)$. Thus, other, as yet unexplored bacterial pathways may contribute to the catecholamine signaling and virulence.

Furthermore, catecholamines act as chemical signals in bacterial chemotaxis, a process in which bacteria navigate along chemical gradients towards attractants and away from repellents (13-15). While the individual components in the chemotaxis signaling cascades vary across different species, the core of the signaling complex typically consists of a transmembrane chemoreceptor (methyl-accepting chemotaxis protein, $\mathrm{MCP}$ ) and a histidine kinase $\mathrm{CheA}$, the two of which are bridged by the coupling protein CheW (16). In response to chemical stimuli, this complex controls the autophosphorylation of CheA, which consequently transfers its phosphoryl group to the response regulator CheY. Phosphorylated CheY induces clockwise rotation of the flagellar motor and, thereby, increases the frequency of tumbling in E. coli. Notably, NE behaved as a weak 
attractant at low concentrations, and as a repellent at higher concentrations $(1 \mathrm{mM})$ and this response appeared not to be mediated by specific binding to a MCP in E. coli (17). Vibrio campbellii (previously $V$. harveyi) ATCC BAA-1116 (18) is an important model organism for quorum sensing (1921). It is a marine, motile, bioluminescent $y$-proteobacterium and an opportunistic pathogen for fish, shrimp, squid, and other marine invertebrates (22). The presence of NE and dopamine increased not only its growth in serumsupplemented medium, but also siderophore production, swimming motility, and expression of genes involved in biofilm formation and virulence (5). Interestingly, antagonists of the mammalian $\alpha$-adrenoceptors such as labetalol (LAB), inhibited the effect of NE on motility, whereas $\beta$ adrenoceptor antagonists such as propranolol (PRO) had no effect, suggesting that catecholamines act via a specific receptor in $V$. campbellii (5). Motility has long been recognized to be important for both commensals and pathogens to colonize their host. In particular, non-motile mutants of different pathogenic Vibrio species showed reduced virulence (23). While the effect of catecholamines on growth most likely stems from the iron-sequestering properties of the catechol siderophore (24), diverging reports exist about the mechanism underlying the altered virulence $(4,5,25)$.

In this study, we applied chemical proteomics to identify protein targets of catecholamine hormones in the model organism V. campbellii. First, we studied the effects of NE, EPI, and a set of chemically related structures as well as the adrenergic antagonists LAB and PRO on growth and motility. The $\alpha$-adrenoceptor agonist phenylephrine (PE) promoted colony expansion without facilitating iron-uptake. Therefore, a corresponding chemical probe was used for subsequent photoaffinity labeling, which revealed the chemotaxis coupling protein $\mathrm{CheW}$ as a major target. Binding of catecholamines to purified CheW was confirmed by Microscale Thermophoresis (MST). The adrenergic agonists EPI, NE, and PE also influenced the chemotactic control of $V$. campbellii, suggesting a new role of eukaryotic host signals on the physiology of bacteria.

\section{Results}

Effects of Catecholamines and Related Compounds on Colony Expansion of V. campbellii on Semisolid (Soft) Agar

We first tested the effect of the hormones EPI and NE and structurally related compounds on a readily detectable phenotype of $V$. campbellii. As previously shown for NE (5), NE, but even more strongly EPI, stimulated swimming motility of $V$. campbellii as measured by colony expansion on semisolid (soft) agar (Fig. 1A-B). PE, a synthetic agonist of human $\alpha$-adrenoceptors elicited a similar increase of colony expansion as the natural hormones, whereas its para-substituted analog, octopamine (OA), a neurotransmitter of invertebrates, had no significant effect (Fig. 1A-B). In addition, we included the adrenergic antagonists LAB (mammalian $\alpha$ - and $\beta$-adrenoceptor specificity) and PRO ( $\beta$-adrenoceptor specificity) (Fig. $1 A$ ). LAB has been reported to antagonize adrenergic effects in V. campbellii while PRO showed no effect (5). Consistent with this literature report, the stimulation of colony expansion by EPI, NE, and PE was blocked by LAB but not by PRO (Fig. 1C). These results indicate the presence of a specific adrenergic sensor that, analogously to the mammalian receptor, can be activated by NE, EPI, and PE and blocked by LAB.

\section{Design and Synthesis of Tailored Probes for Chemical Proteomic Studies}

To decipher the cellular targets of catecholamine hormones, we designed and synthesized chemical probes containing an alkyne handle suitable for target protein enrichment via affinity-based protein profiling (AfBPP) (26-28). As we could not exclude that the probe scaffold binds reversibly, we appended an alkyne-containing minimalist photocrosslinker to the EPI-based probe EPI-P1 via alkylation of NE at the amine (Fig. 1A, and SI Appendix, Fig. S1A) (29). Here the synthesis was challenged by the instability of catecholamines. At neutral to basic $\mathrm{pH}$ the catechol group is easily oxidized to an ortho-quinone, which can be attacked by the amine (30). This required purification under acidic conditions, resulting in a residual amount of acetic acid in the product needed for stability. Thus, in a second generation of probes we used direct acylation of catecholamines which yielded more stable products. Moreover, as we observed an inherent photoreactivity of the adrenergic compounds, we omitted the diazirine and appended an alkyne handle to the terminal amine of NE, norphenylephrine, and OA by standard amide coupling, yielding probes EPI-P2, PE-P, and OA-P, respectively (Fig. $1 A$, SI Appendix, Fig. S1B). Next, the derivatives were tested in soft agar motility assays where enhanced colony expansion was confirmed for probes EPI-P1 (6-60 $\mu \mathrm{M})$, EPI-P2 $(10-25 \mu \mathrm{M})$, and PE-P $(10-50 \mu \mathrm{M})$, suggesting that these probes retain suitable biological activity to unravel their cellular targets (Fig. 1D, SI Appendix, Fig. S2). For EPIP2 and PE-P, a drop in activity was observed at concentrations above $25 \mu \mathrm{M}$ and $50 \mu \mathrm{M}$, respectively (SI Appendix, Fig. S2 B-C). In contrast to its parent compound OA, OA-P proved slightly active $(25-100 \mu \mathrm{M})$, although still to a lesser extent than the other probes ( $S$ I Appendix, Fig. S2D). 
A

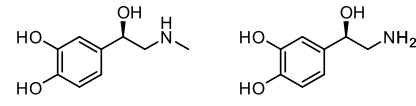

EPI<smiles>CNCC(O)c1cccc(O)c1</smiles>

PE

B

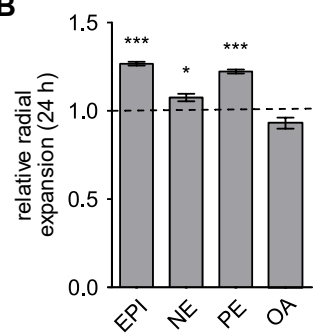

E

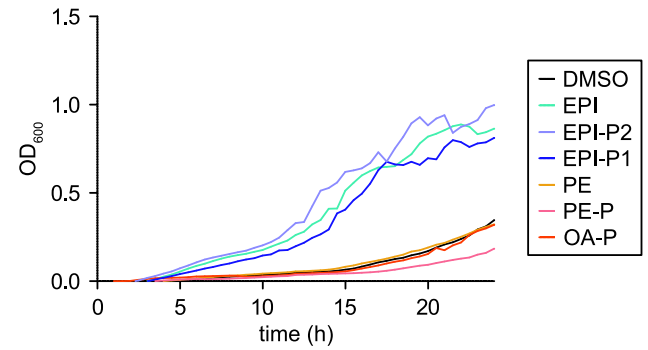<smiles>CC(CCc1ccccc1)NC(C)c1ccc(O)c(C(N)=O)c1</smiles><smiles></smiles>

PRO

c

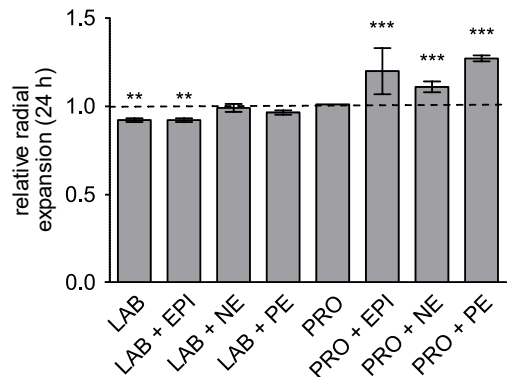

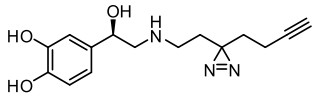

EPI-P1<smiles>C=CCCCC(=O)NCc1cccc(O)c1</smiles><smiles>C=CCCCC(=O)NCC(C)c1ccc(O)cc1</smiles>

D

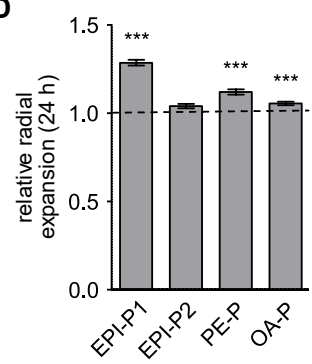

F
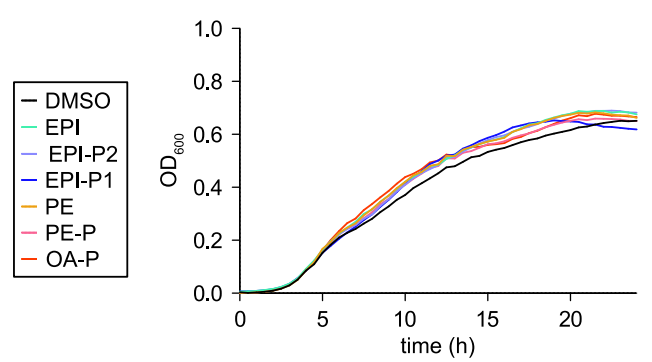

Figure 1. Bioactivity assays of catecholamines and related compounds. $(A)$ Structures of parent compounds EPI, NE, PE, and OA, adrenergic antagonists LAB and PRO, and probes EPI-P1, EPI-P2, PE-P, and OA-P. (B) Soft agar colony expansion assays with EPI, NE, PE, and OA at $50 \mu \mathrm{M}$. Radial expansions were normalized to an untreated control. Error bars represent the standard deviation from six independent experiments. Significance was determined performing a oneway ANOVA with Tukey's post hoc test $\left({ }^{*}=p<0.05,{ }^{* *}=p<0.01,{ }^{* * *}=p<0.001\right)$. (C) Soft agar colony expansion assay with EPI, NE, or PE $(50 \mu \mathrm{M})$ in presence of adrenergic antagonists PRO or LAB $(50 \mu \mathrm{M})$. (D) Soft agar colony expansion assays using chemical probes EPI-P1, EPI-P2, PE-P, and OA-P $(50-60 \mu \mathrm{M})(E)$ Growth of bacteria in LB35 medium supplemented with $30 \%(\mathrm{v} / \mathrm{v})$ adult calf serum in 96-well microtiter plates with interval shaking at $30^{\circ} \mathrm{C}$. Compounds were added at a concentration of $50 \mu \mathrm{M}$. Data show the average of technical triplicates. ( $F$ ) Growth assay with serum-free LB35 medium under the same conditions as indicated in $E$.

\section{Catechol-bearing Probes Have Iron-Chelating Properties}

In the body fluids of eukaryotic hosts, bacterial growth is limited by extremely low levels of available iron, a phenomenon known as nutritional immunity (31). Iron limitation is achieved by high-affinity iron-binding proteins such as transferrin and lactoferrin. Nevertheless, bacteria are able to acquire iron via iron-binding molecules, so-called siderophores, either synthesized by the bacteria or scavenged from the environment. Among the most common classes of siderophores are catecholates, which include the bacterial enterobactin, but also catecholamine hormones
(24, 32-34). We therefore tested the siderophore effects of our probes and their parent compounds on the growth of $V$. campbellii. These assays were performed in serumsupplemented medium, a set-up typically used to mimic the iron-limited conditions encountered by the bacteria in eukaryotic hosts (34). As expected, catechol-containing compounds EPI-P1, EPI-P2, and EPI enhanced growth while all other compounds including PE-P did not have an effect (Fig. 1E). A comparable growth stimulation was not observed when the bacteria were grown in serum-free medium, indicating that the growth-stimulating effect of catecholamines is due to their ability to sequester iron (Fig. 1F). 
A

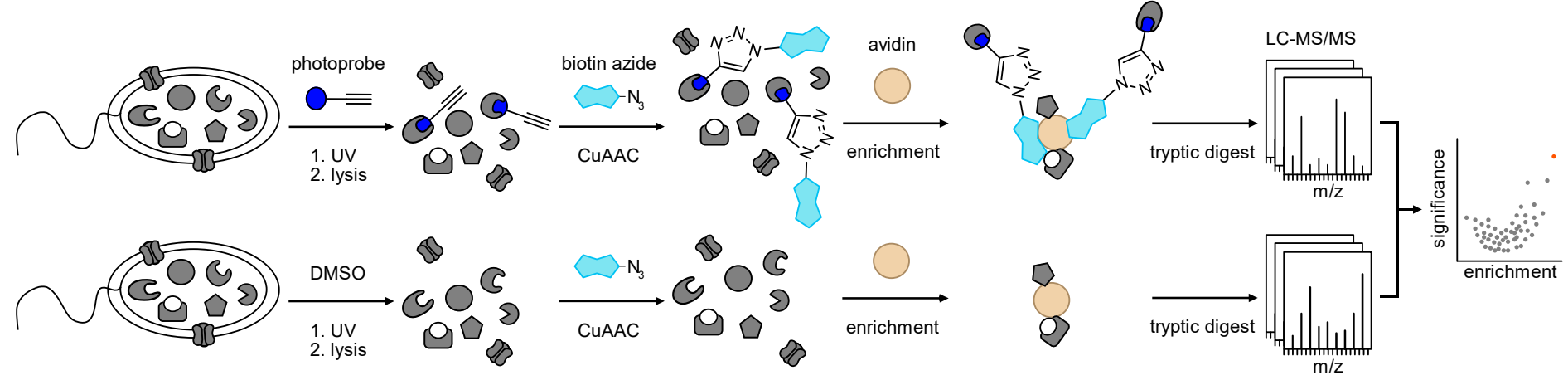

B

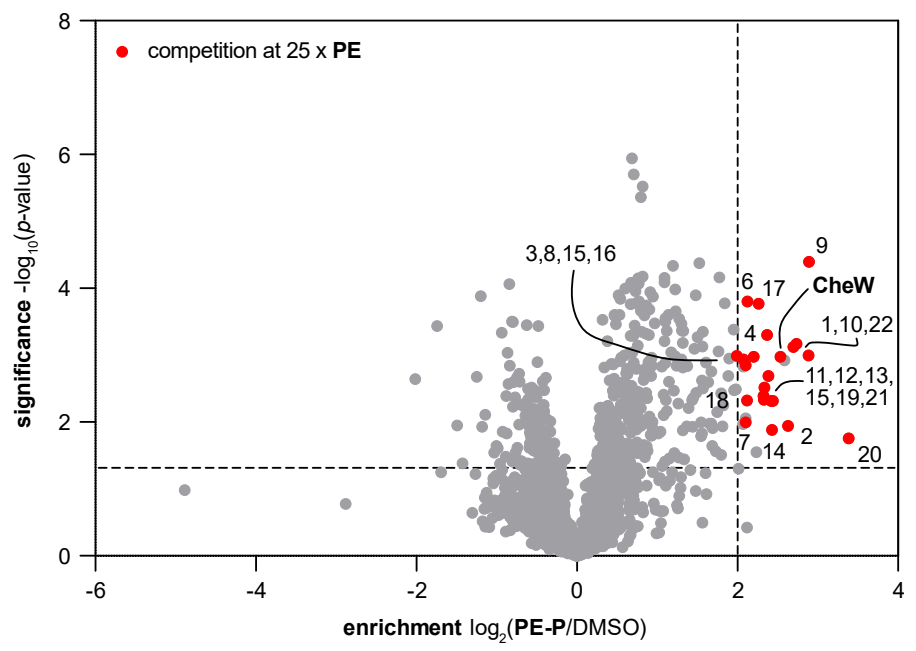

\begin{tabular}{rlll}
\hline legend & UniProt & gene & protein name \\
\hline CheW & A7MS42 & VIBHAR_03137 & $\begin{array}{l}\text { CheW-like domain-containing } \\
\text { protein }\end{array}$ \\
1 & A7MSA8 & VIBHAR_03672 & UPF0307 protein VIBHAR_03672 \\
2 & A7MT63 & VIBHAR_01308 & HPr domain-containin g protein \\
3 & A7MTV7 & yihl & Der GTPase-activating protein Yihl \\
4 & A7MUD0 & VIBHAR_02658 & Uncharact erized \\
5 & A7MUJ3 & VIBHAR_03027 & UPF0352 protein VIBHAR_03027 \\
6 & A7MV84 & tig & Trigger factor \\
7 & A7MWU1 & nusB & Transcription antitermination prot. NusB \\
8 & A7MWW5 & grpE & Protein GrpE \\
9 & A7MWX0 & VIBHAR_01126 & UPF0125 protein VIBHAR_01126 \\
10 & A7MX55 & groS & 10 kDa chaperonin \\
11 & A7MXE6 & nusG & Transcr. termin./antitermin. prot. NusG \\
12 & A7MXS1 & VIBHAR_00356 & Uncharact erized \\
13 & A7MYT1 & VIBHAR_01892 & Uncharact erized \\
14 & A7MYT3 & CsrA & Translational regulator CsrA \\
15 & A7MZ63 & rpsG & 30S ribosomal protein S7 \\
16 & A7MZ14 & rbfA & Riboso me-binding fa ctor A \\
17 & A7N1J5 & VIBHAR_01583 & Uncharact erized \\
18 & A7N1L7 & infA & Translation initiati on factor IF-1 \\
19 & A7N2H7 & VIBHAR_05151 & Uncharact erized \\
20 & A7N3V9 & VIBHAR_05396 & CSD domain-containing protein \\
21 & A7N3X4 & VIBHAR_05367 & Phasin_2 domain-containing protein \\
22 & A7N8F2 & VIBHAR_06507 & Uncharact erized \\
\hline & & & \\
\hline
\end{tabular}

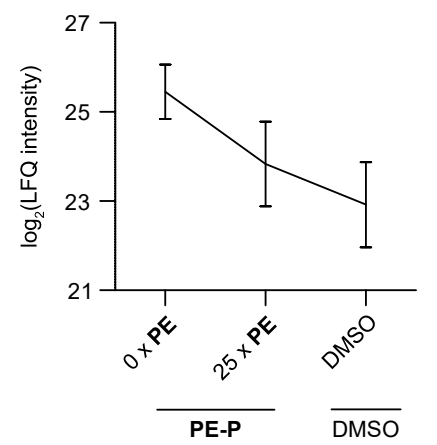

D

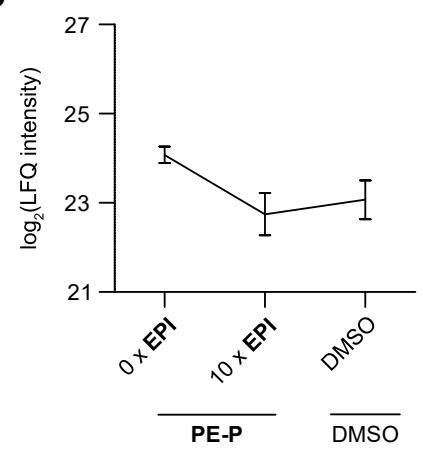

$\mathbf{E}$

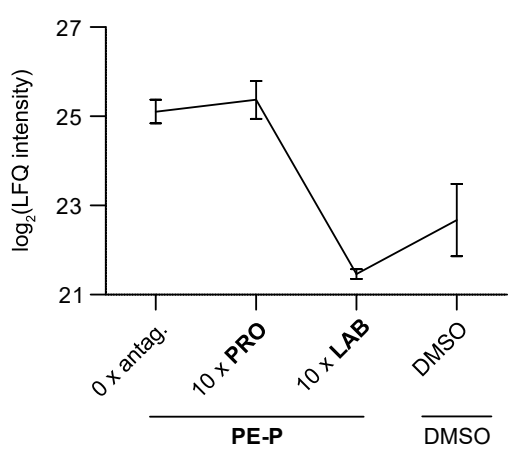

Figure 2. CheW is identified as a potential adrenergic target by photoaffinity labeling with PE-P. $(A)$ Chemical proteomics workflow applied for target identification. Live bacteria were treated with $10 \mu \mathrm{M}$ PE-P, or DMSO as control, or PE-P plus increasing concentrations of competitors (PE, EPI, LAB, PRO), irradiated, lysed, separated into soluble (PBS) and insoluble proteins, ligated by CuAAC to biotin azide, enriched on avidin beads, digested, and peptides were analyzed by LC-MS/MS. (B) Volcano plot showing proteins enriched in samples treated with $10 \mu \mathrm{M}$ PE-P over DMSO controls. Proteins outcompeted by a 25-fold excess of PE are highlighted in red; the experiment was done in five biological replicates. MS Data were analyzed by MaxLFQ (38), filtered for proteins identified in four replicates, and missing values were imputed. Samples were compared using a two-sample permutation-corrected $t$-test. $(C)$ Profile plot of CheW LFQ intensities from competition with a 25-fold excess of PE. Error bars denote standard deviation, $\mathrm{n}=5$ biological replicates. $(D)$ Profile plot of CheW LFQ intensities from competition with a 10-fold excess of EPI, $n=4$ biological replicates. (E) Profile plot from competition with a 10 -fold excess of PRO or LAB, $n=4$ biological replicates. All data shown here are from the insoluble fraction. See $S I$ Appendix, Fig. S5-S7 for more detailed competition data and soluble fractions. 


\section{Photolabeling Reveals the Chemotaxis Protein CheW as a Potential Adrenergic Target}

Prior to MS-based proteome profiling we investigated general protein labeling of intact $V$. campbellii cells with EPIP1, EPI-P2, PE-P, and OA-P, respectively, via gel-based fluorescence analysis of the proteomes. Live cells were incubated with $50 \mu \mathrm{M}$ of probes and irradiated with UV-light to enable covalent bond formation of the probe to the target proteins. Following cell lysis, the proteome was separated into a PBS-soluble fraction, containing primarily cytosolic proteins, and a PBS-insoluble fraction, containing cytosolic and membrane proteins, and both fractions were subjected to copper-catalyzed azide-alkyne cycloaddition (CuAAC) to append a fluorescent tag to the labeled proteins $(36,37)$. Labeled proteins were separated by SDS-PAGE and visualized by in-gel fluorescence scanning. Interestingly, labeling was observed in both fractions, indicating cellpermeability of the probes (SI Appendix, Fig. S3). Fluorescent SDS-PAGE analysis of EPI-P1 and EPI-P2 treated cells showed labeling both in presence and absence of UV, albeit to a lesser extent in the latter case. The general reactivity of EPI-P1 and EPI-P2 towards proteins is likely attributed to the catechol moiety, which is known to form an electrophilic ortho-quinone upon oxidation even in the absence of UV-light (30). Consistent with its lack of a catechol moiety, PE-P strongly labeled proteins solely upon UV-irradiation, suggesting a so far undiscovered photoreactivity of the molecule. Almost no protein reactivity was observed for OA-P, which is in line with its weak bioactivity and it was therefore excluded from further analysis.

We selected EPI-P1 and PE-P for further studies as both exhibited a distinct labeling profile and activity in the motility assays. With two adrenergic probes at hand, we studied their cellular target proteins via quantitative LC-MS/MS analysis (Fig. 2A). Treatment of live $V$. campbellii with EPI-P1 or PE-P was followed by UV-irradiation, cell-lysis, CuAAC to biotin azide, enrichment on avidin beads, and tryptic digest, resulting in peptides, which were measured by LC-MS/MS with label-free quantification (LFQ) (38). All proteins which were significantly $\left(-\log _{10}(p\right.$-value $\left.) \geq 1.3\right)$ enriched by at least 2-fold in the probe-treated samples compared to the DMSO controls are visualized in the upper right quadrant of the corresponding volcano plot. EPI-P1 enriched, among others, an outer membrane receptor protein for ferrienterochelin and colicins (A7MZS4) and an iron-hydroxamate $A B C$ transporter substrate binding protein (A7MSY4), indicating that this probe indeed functions as xenosiderophore (SI Appendix, Fig. S4). In fact, CheW was also enriched 3.9-fold in this dataset although it was not among the most prominent hits. We hypothesized that the abundance of iron-uptake proteins interfered with the identification of further adrenergic targets. We therefore switched to labeling studies with PE-P, devoid of the catechol moiety (Fig. 2B). Here, proteins associated with iron uptake were no longer significantly enriched. Importantly, the chemotaxis coupling protein CheW turned out to be one of the most prominent hits. Based on its role in chemotaxis, CheW is an intriguing candidate for catecholamine binding, and it was thus further investigated for displacement of probe binding in the presence of excess concentrations of the unmodified catecholamines. Cells were pre-incubated with different concentrations (10 $250 \mu \mathrm{M}$ ) of PE, EPI, LAB, or PRO before adding PE-P (10 $\mu \mathrm{M})$. EPI, PE, and LAB reduced enrichment of CheW by probe $\mathrm{PE}-\mathrm{P}$ indicating competitive binding and corroborating CheW as a specific target of these compounds (Fig. 2C-E and SI Appendix, Fig. S5-S7). PRO, however, did not compete for binding, consistent with its lack of antagonism in the motility assays (Fig. 2E, SI Appendix, Fig. S7C).

\section{Insights Into the Mechanism of PE-P Binding}

To elucidate the UV-dependent binding mode of PE-P, we performed labeling experiments in the presence of radical scavengers. UV-dependent labeling by PE-P could be fully quenched by the addition of thiourea and tiron, suggesting a light-induced fragmentation of the molecule to form reactive radical intermediates (SI Appendix, Fig. S8). To further assess the nature of radical binding to proteins, we applied a mass-spectrometry method which unravels the modified residues within proteins as well as the type of modification. This technology is based on isotopically labeled desthiobiotin azide (isoDTB) tags, which are clicked to probe-labeled proteins after lysis (39). Proteins are subsequently digested, followed by peptide enrichment on avidin beads, and detection of modified peptides via LC-MS/MS analysis (Fig. 3A) (40). In an unbiased analysis (41), we detected modified peptides with the added mass of the adduct with PE-P plus light or heavy isoDTB tag, respectively (Fig. $3 B$ ). Interestingly, we observed a high selectivity for tyrosine, which constituted $90 \%$ of all detected modified residues, corroborating a radical mechanism of binding (Fig. $3 C$ and $D$ ).

\section{Validation of Catecholamine Binding to CheW and Analysis of the CheW Interaction Network}

To validate catecholamine binding to $\mathrm{CheW}$, we measured the affinity of the ligands for CheW using Microscale Thermophoresis (MST) (42). For this purpose, CheW was recombinantly expressed in $E$. coli, purified, and fluorescently labeled. Temperature-induced changes in fluorescence (temperature-related intensity changes and/or temperature dependent movements) were determined as a function of ligand concentration in glass capillaries. The 
A

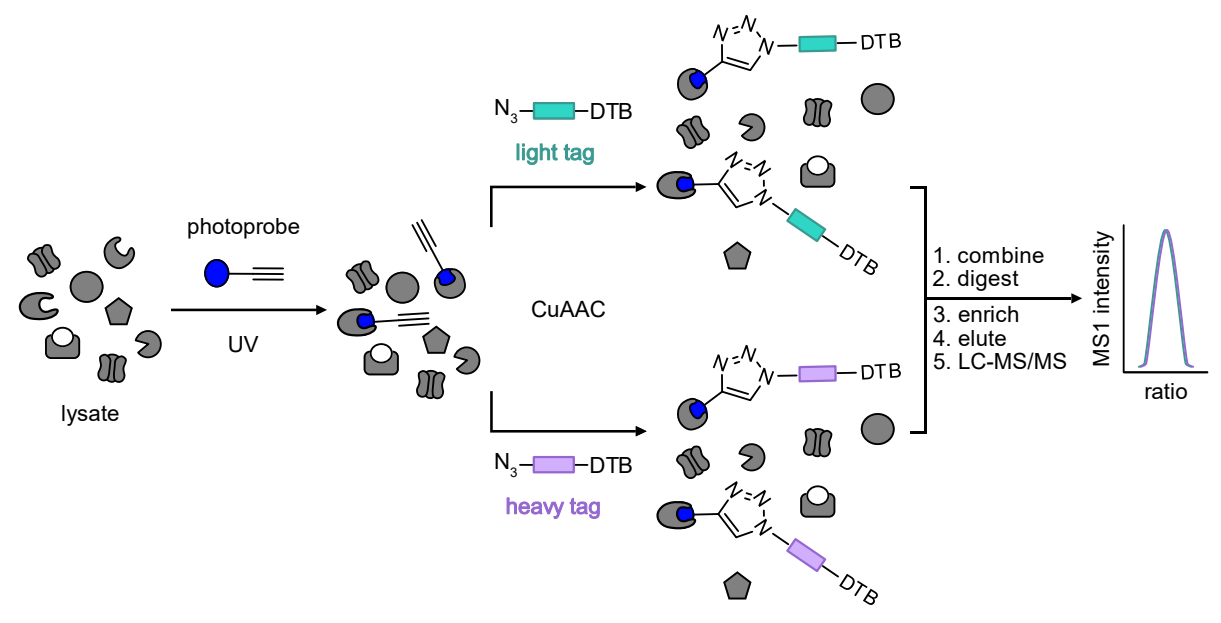

B

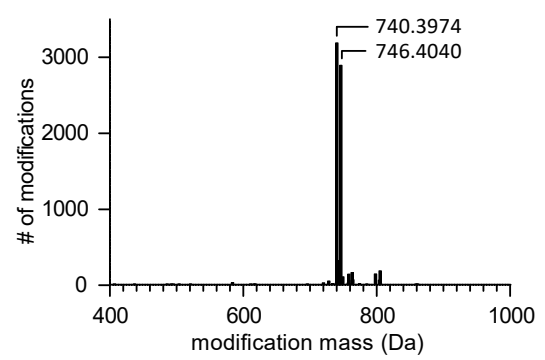

C

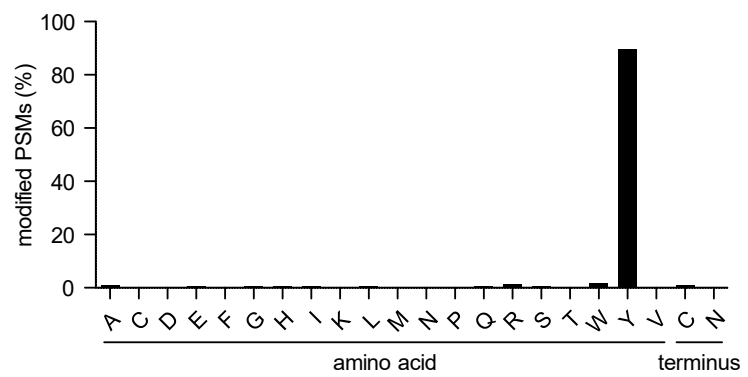

D

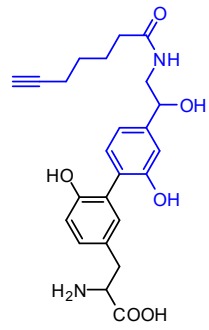

Figure 3. Analysis of the modifications introduced by PE-P proteome-wide. ( $A$ ) Workflow applied to study binding mode and sites of PE-P using isotopically labeled desthiobiotin (isoDTB) tags $(39,41)$. V. campbellii lysate was treated with $10 \mu \mathrm{M}$ PE-P (blue circle), irradiated, split, and subjected to CuAAC with either light- (turquoise rectangle) or heavy-labeled (purple rectangle) isoDTB azide. Differentially labeled lysates were combined in a ratio of 1:1, proteins precipitated, and digested. Modified peptides were enriched on avidin, eluted, and analyzed by LC-MS/MS. Peptides detected with a ratio of close to 1:1 heavy:light tag were considered true hits. $(B)$ Unbiased, proteome-wide analysis of the masses of modification introduced by PE-P and the light or heavy isoDTB tag, respectively. (C) Analysis of the amino acid selectivity of the detected modification with PE-P. PSM = peptide spectrum matches. (D) Potential structure of the modified tyrosine regioisomer corresponding to the observed modification mass. All data are based on technical duplicates.

parent compounds EPI, NE, PE, the adrenergic antagonist $\mathbf{L A B}$, and $\mathbf{O A}$ as negative control were tested as putative ligands. PRO could not be tested due to interference from its intrinsic fluorescence. Interestingly, EPI, NE, PE, and LAB caused concentration-dependent effects on the fluorescently labeled $\mathrm{CheW}$ with dissociation constants $K_{d}$ ranging from $300 \mathrm{nM}$ to $740 \mathrm{nM}$ (Fig. 4A), indicating strong affinity binding. These observations are consistent with the results from the colony expansion and competitive labeling experiments (Fig. $1 B$ and $2 C-F$ ). In line with its lack of activity in the motility assays (Fig. 2C), OA showed no binding affinity for CheW.

Next, protein interaction partners of CheW were studied by co-immunoprecipitation (Co-IP) in cells treated first with 100 $\mu \mathrm{M}$ EPI or DMSO as control and then with DSSO to stabilize interaction partners by covalent crosslinks (43). Numerous proteins annotated to be involved in chemotaxis (GO or
KEGG database) were enriched compared to an isotype control, including CheA, CheZ, MCPs, and a CheW-like domain-containing protein, confirming the validity of the antibody and the methodology ( $S I$ Appendix, Fig. S9A-B). The presence of EPI, however, did not result in any obvious catecholamine-dependent changes of interaction partners (SI Appendix, Fig. S9C). These results suggest that under the conditions tested, binding of catecholamines to CheW does not alter the associated protein networks. This is in line with the observation that transmembrane chemoreceptor arrays remain intact upon activation (44).

\section{Adrenergic Compounds Affect the Chemotactic Control of $V$. campbellii}

To gain deeper insights into the effect of EPI and PE on colony expansion on soft agar (Fig. 1) and chemotaxis, we 


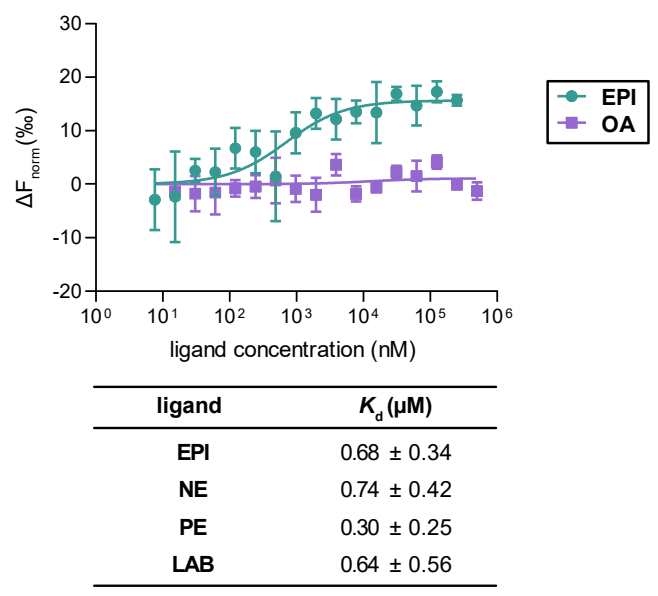

D
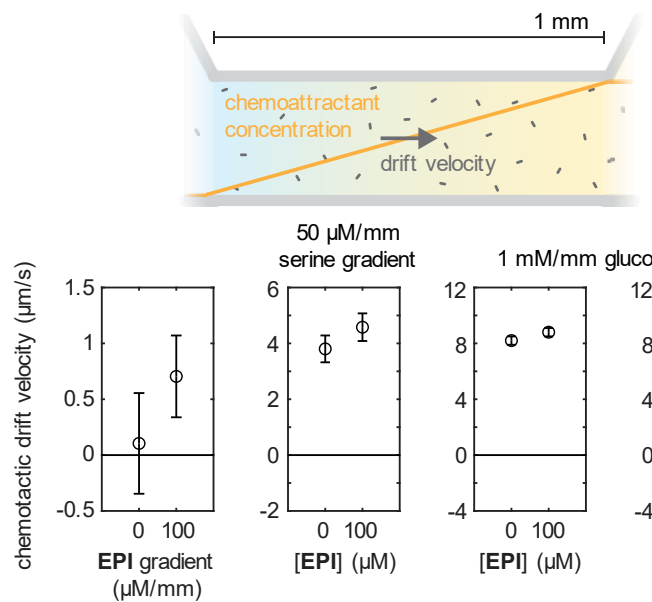

$50 \mu \mathrm{M} / \mathrm{mm}$
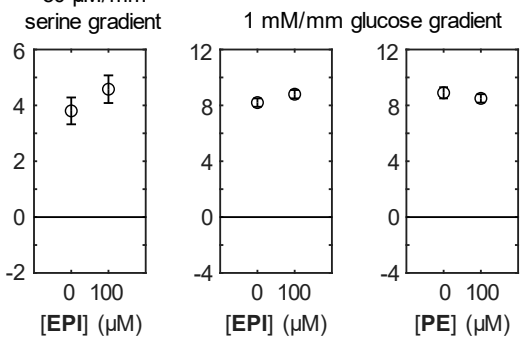

C
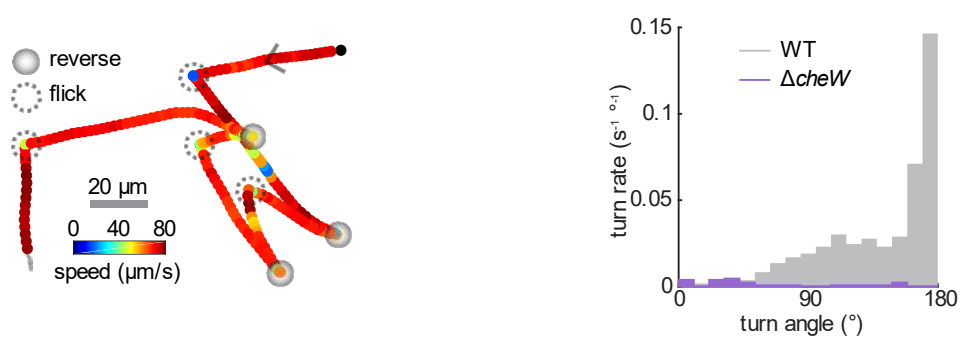

E

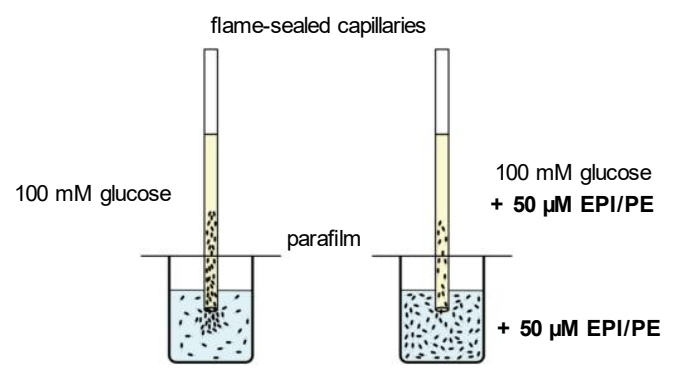

bottom of 96-well plate

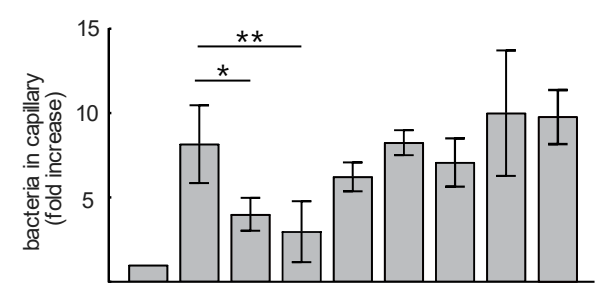

capillary: H-ASW Glc Glc Glc Glc Glc Glc Glc Glc well: - - EPI PE NE LABPRO OA EPI

$\stackrel{+}{L A B}$

Figure 4. Binding of adrenergic compounds to $\mathrm{CheW}$ in vitro and their effect on motility and chemotaxis of $V$. campbellii in vivo. (A) Binding of adrenergic compounds to purified CheW was determined using Microscale Thermophoresis (MST). Increasing concentrations of the test compounds $(\mathrm{c}=7.63 \mathrm{nM}-500 \mu \mathrm{M})$ were titrated to a constant concentration of fluorescently labeled CheW $(c=50 \mathrm{nM})$, and temperature-induced changes in fluorescence were monitored in glass capillaries using the Monolith NT.115 (NanoTemper Technologies). Kd values were determined using the Thermophoresis + T-Jump signal for data analysis (NT Analysis software version 1.5.41, NanoTemper Technologies, $\mathrm{n}=3$ independent measurements, error bars represent standard deviation). (B) Example 3D trajectory of $V$. campbellii showing run-reverseflick motility with turns alternating between reversals and flicks. (C) Rate of turn events as a function of turn angle for wild type (WT) and the $\Delta$ cheW mutant, based on 1,447 turn events detected in 1,295 s of trajectory time for WT and 29 events in 3,250 s of trajectory time for $\Delta c h e W$. (D) The 3D chemotaxis assay was performed by $3 \mathrm{D}$ tracking of cells in linear chemical gradients established in a $1 \mathrm{~mm}$ long channel between two reservoirs of different chemical, but matched bacterial concentration (concept is schematically shown in the upper part). The drift velocity was determined as the average speed of motile cells along the gradient direction. Error bars represent standard deviations of the mean. (E) In the capillary chemotaxis assay bacteria swim from a reservoir in a microtiter plate into a glass capillary filled with an attractant (100 mM glucose) (concept is schematically shown in the upper part). After $60 \mathrm{~min}$, the number of bacteria in the capillary was determined by plating the cells on agar plates. The concentration of EPI and structurally related compounds was constant $(50 \mu \mathrm{M})$ in the capillary and reservoir. Values were normalized to their respective control (HEPES-buffered artificial sea water, $\mathrm{H}$-ASW). Error bars represent standard deviation of the mean, $\mathrm{n}=4$ biological replicates. Statistical significance was determined using a one-way ANOVA analysis $\left({ }^{*}=p<0.05,{ }^{* *}=p<0.01\right)$. 
first used 3D tracking to examine the motility of untreated $V$. campbellii cells of the mid-exponential growth phase. Similar to Vibrio alginolyticus (45), the cells exhibited a run-reverseflick pattern at typical swimming speeds of $54 \pm 2 \mu \mathrm{m} / \mathrm{s}$ and a steady-state turning frequency of $0.52 \pm 0.03 \mathrm{~s}^{-1}$ (Fig. 4B). We did not detect any significant effects of EPI on the average speed or steady-state turning frequency ( $S I$ Appendix, Fig. S10). Since EPI and PE bind to CheW, we next examined the motility of a $\Delta c h e W$ mutant. The $\Delta c h e W$ mutant had a similar average swimming speed as the wild type (48 $\pm 4 \mu \mathrm{m} / \mathrm{s})$, but proved to be a smooth swimmer with a very low turning frequency (Fig. $4 C$ ). This mutant was unable to spread on soft agar (SI Appendix, Fig. S11), a phenomenon previously observed in other Vibrio species (46). Next, we used a multiscale 3D chemotaxis assay (47) that combines high-throughput 3D bacterial tracking with a microfluidically created linear chemical gradient (Fig. 4D). A $100 \mu \mathrm{M} / \mathrm{mm}$ EPI gradient elicited a weak chemoattractant response (positive chemotactic drift). Serine $(50 \mu \mathrm{M} / \mathrm{mm})$ and glucose $(1 \mathrm{mM} / \mathrm{mm})$, respectively, were recognized as stronger chemoattractants, and the presence of EPI or PE had no effect on the chemotactic drift (Fig. 4D).

Finally, we used a capillary chemotaxis assay originally developed for E. coli (48). Briefly, in this assay, a glass capillary filled with an attractant is inserted into a cell suspension and the number of cells in the capillary is counted after 60 minutes of incubation (Fig. 4E). Using this assay, we detected a chemotactic response of $V$. campbellii to chitin, glucose, and serine (SI Appendix, Fig. S12). Although this assay is not as sensitive as the 3D microfluidic chemotaxis assay (thus requiring higher concentrations of the chemoattractant), we found a significant reduction in cell numbers in the glucose-filled capillary in the presence of EPI and PE, whereas NE, LAB, PRO and OA did not show an effect (Fig. 4E). Furthermore, the effect of EPI was suppressed in the presence of LAB. These results are consistent with the specific effect of EPI, PE, and EPI + LAB on colony expansion (Fig. 1B) and suggest that binding of EPI or PE to CheW affects the swimming behavior of $V$. campbellii in chemical gradients over long distances.

\section{Discussion}

In this study, we report the direct binding of the eukaryotic stress hormone EPI to CheW, the coupling protein between MCPs and CheA, located in the core of the chemotaxis signaling network in $V$. campbellii. It is known that mammalian host stress associated with the release of catecholamine hormones not only increases susceptibility to bacterial infection, but that EPI and NE also stimulate the growth and motility of enterobacteria such as $S$. Typhimurium, E. coli, and V. cholerae (1-4). We used an untargeted chemical proteomics approach to identify the cellular targets of EPI. We chose PE, which is a structural homolog of EPI, for probe design as it still promotes colony expansion but cannot bind iron (Fig. 1). In these studies, the chemotaxis coupling protein CheW proved to be one of the most prominent hits. This finding was confirmed by competitive labeling in the presence of EPI, PE, and LAB, the latter being a clinically applied antagonist of $\alpha$ adrenergic receptors in eukaryotes. We also demonstrated direct binding of EPI, NE, PE, and LAB to purified CheW. The binding of EPI to CheW is an unexpected discovery, but nevertheless consolidates previous reports seeking to find a specific chemoreceptor for catecholamines. For example, a $V$. cholerae mutant lacking the $q s e C$-like gene still responded to catecholamines (4). Based on studies on the influence of catecholamines on chemotaxis, Sourjik and coworkers proposed that in E. coli these hormones are sensed by a mechanism other than specific binding to a MCP (17).

The $\Delta$ cheW mutant of $V$. campbellii is motile but has an extremely low turning frequency and it is non-chemotactic (Fig. 4B, SI Appendix, Fig. S12). This finding is consistent with results for many other bacterial species that lack cheW (summarized in Alexander et al., 2010 (49)). Our 3D tracking assays revealed that EPI does not affect the turning rate or swimming speed of wild-type $V$. campbellii but acts as a weak attractant. These results indicate that binding of EPI to CheW does not phenocopy the behavior of the $\Delta$ cheW mutant (Fig. 4). However, in the capillary assay, which depends on the motility and chemotactic behavior of a population over large distances, the presence of EPI and PE leads to a significant decrease in the accumulation of cells in the glucose-filled capillary. This effect is specific for EPI and PE, because the presence of NE, LAB, PRO, and OA did not affect the movement of the cells along the glucose gradient. Interestingly, LAB, which binds to CheW, prevents the effect of EPI and PE both in the capillary-based chemotaxis and in the soft agar assays. The lack of activity of LAB itself is reminiscent of the behavior of classical pharmacological antagonists, which typically block agonist activity by binding to their target proteins but without exerting any effects themselves. Similar to its weak effect on colony expansion, NE was barely active in the capillary-based chemotaxis assay. As determined by MST, NE had a lower affinity for CheW compared to all tested compounds, which could explain these observations. Overall, our results suggest that binding of EPI and PE to CheW influences the chemotactic control of the bacterium.

Both chemotaxis and net motility are known to affect the infectivity of $V$. cholerae (50). The results described here could potentially provide an explanation for the hyperinfective transient phenotype of stool-derived $V$. cholerae (51-53). Although the stool-derived $V$. cholerae are highly motile, many chemotaxis genes including cheW and che $R$ are repressed compared to in vitro grown cells 
resulting in a smooth-swimming state. Our finding that EPI targets CheW suggests a novel mechanism for such hosttriggered phenotypes.

\section{Materials and Methods}

Chemical synthesis. For synthetic procedures and compound characterization data see SI Appendix, supplementary methods, Fig. S1, and Fig. S13-S17.

General information. Detailed information on compounds, bacterial strains, culture conditions, preparation of overnight cultures, and media composition are provided in the $S I$ Appendix, supplementary methods, Table S1-S3 and Table S5.

Growth assays. A $V$. campbellii overnight culture was diluted 1:100 into fresh LB35 medium $(60 \mathrm{~mL})$ and grown until early stationary phase $\left(8 \mathrm{~h}, \mathrm{OD}_{600} \sim 5.0\right)$. Compounds $(1 \mu \mathrm{L} 10 \mathrm{mM}$ stock in DMSO for $50 \mu \mathrm{M}$ final concentration) were dispensed into a clear flat-bottom 96-well plate (Thermo Scientific) and $199 \mu \mathrm{L}$ of bacterial culture previously diluted to $\mathrm{OD}_{600} 0.005$ in LB35 or in LB35 supplemented with $30 \%(\mathrm{v} / \mathrm{v})$ of adult bovine serum (Sigma) was added. The plate was incubated in an Infinite $\AA$ M200 Pro plate reader (Tecan) at $30^{\circ} \mathrm{C}$ with $20 \mathrm{~s}$ shaking every 5 $\mathrm{min}$. The absorbance at $600 \mathrm{~nm}$ was measured every 30 min. Blank values (only medium) were subtracted from data values and data were plotted in GraphPad Prism 5.03.

Soft agar colony expansion assay. Soft agar colony expansion assays were performed as described previously on LB35 plates containing $0.3 \% \quad(\mathrm{w} / \mathrm{v})$ agar (5). Catecholamines and antagonists were dissolved in water and added as supplements directly to the autoclaved medium before pouring plates. As control, the appropriate volume of water was added to the plates. V. campbellii overnight culture was diluted in fresh LB35 $\left(\mathrm{OD}_{600}=1\right)$ and $5 \mu \mathrm{L}$ was dropped in the center of the plate with six independent replicates for each condition. After an incubation of $24 \mathrm{~h}$ at $30{ }^{\circ} \mathrm{C}$ the expansion of the colony (diameter) was measured. Radial expansions were normalized to an untreated control and significance was determined performing a one-way ANOVA with Tukey's post hoc test.

Preparative photolabeling with PE-P. Overnight cultures of $V$. campbellii were diluted $1: 100$ into $60 \mathrm{~mL}$ fresh medium and grown until early stationary phase $\left(30^{\circ} \mathrm{C}, 200 \mathrm{rpm}, 7 \mathrm{~h}\right.$, $\left.\mathrm{OD}_{600} \sim 5.0-5.2\right)$. Bacteria were harvested by centrifugation $\left(6,000 \times \mathrm{g}, 10 \mathrm{~min}, 4^{\circ} \mathrm{C}\right)$, washed with PBS $(10 \mathrm{~mL})$, and adjusted to $\mathrm{OD}_{600} 4.0$ in $10 \mathrm{~mL}$ PBS. Competitors PE, EPI, LAB, PRO or DMSO were added from 1,000-fold concentrated DMSO stocks to the final concentrations as indicated and the suspensions were incubated $15 \mathrm{~min}$, $30^{\circ} \mathrm{C}, 200 \mathrm{rpm}$ in $50 \mathrm{~mL}$ centrifuge tubes with the lids fixed loosely. Next, DMSO or the photoprobe PE-P was added from a 1,000 -fold concentrated stock $(10 \mathrm{mM})$ to a final concentration of $10 \mu \mathrm{M}$ and incubated $1 \mathrm{~h}, 30^{\circ} \mathrm{C}, 200 \mathrm{rpm}$. Samples were transferred to $10 \mathrm{~cm}$ dishes and irradiated for 10 min with UV light (UV low-pressure mercury-vapor fluorescent lamp, Philips TL-D 18W BLB, $360 \mathrm{~nm}$ maximum) on a cooling pack. Labeled bacteria were centrifuged $(6,000$ $\mathrm{xg}, 10 \mathrm{~min}, 4^{\circ} \mathrm{C}$ ) and the pellet was washed twice with cold PBS $(1 \mathrm{~mL})$. Pellets were flash-frozen and stored at $-80^{\circ} \mathrm{C}$. Pellets were resuspended in $1 \mathrm{~mL}$ PBS + EDTA-free protease inhibitor (Roche) and sonicated $2 \times 15 \mathrm{~s}, 60 \%$ intensity, on ice. Following centrifugation $(16,060 \times g$, $30 \mathrm{~min}, 4^{\circ} \mathrm{C}$ ), the supernatant was removed ("soluble") and the pellet was resuspended in $1 \%(\mathrm{w} / \mathrm{v})$ SDS/PBS with sonication for $2 \times 15 \mathrm{~s}, 40 \%$ intensity. Cell debris was pelleted $(16,060 \times g, 10 \mathrm{~min}, \mathrm{RT})$ and the supernatant was transferred into a new tube ("insoluble"). For analytical scale photolabeling and preparative photolabeling with EPI-P1 see SI Appendix.

CuAAC, preparative scale photolabeling. Protein concentration was determined using the Roti ${ }^{\circledR}$-Quant kit (Carl Roth) and adjusted to $\sim 1 \mu \mathrm{g} / \mu \mathrm{L}$ in $500 \mu \mathrm{L}$. SDS was added to $0.8 \%(\mathrm{w} / \mathrm{v})$ in the "soluble" samples. Click reagents were added to the lysate from a premix to the following concentrations: $100 \mu \mathrm{M}$ rhodamine-biotin-azide tag (54) (10 $\mathrm{mM}$ stock in DMSO), $1 \mathrm{mM} \mathrm{CuSO}_{4}$ (50 mM stock in water), $1 \mathrm{mM}$ tris(2-carboxyethyl)phosphine hydrochloride (TCEP, $52 \mathrm{mM}$ stock in water), and $100 \mu \mathrm{M}$ tris((1-benzyl-4triazolyl)methyl)amine (TBTA, $1.667 \mathrm{mM}$ stock in 20\% (v/v) $\mathrm{DMSO} / \mathrm{t}-\mathrm{BuOH}$ ) and incubated $1 \mathrm{~h}, 25^{\circ} \mathrm{C}, 400 \mathrm{rpm}$. Proteins were precipitated in $2 \mathrm{~mL}$ acetone at $-20^{\circ} \mathrm{C}$ overnight, pelleted $\left(20,450 \times g 15 \mathrm{~min}, 4^{\circ} \mathrm{C}\right)$, and washed twice with 1 $\mathrm{mL}$ ice-cold methanol with sonication $(1 \times 10 \mathrm{~s}, 10 \%$ intensity). Pellets were air-dried, proteins resolubilized in 1 $\mathrm{mM}$ DTT, $0.2 \%(\mathrm{w} / \mathrm{v})$ SDS/PBS with sonication $(1 \times 10 \mathrm{~s}$, $10 \%$ intensity), and transferred to LoBind microcentrifuge tubes.

MS sample preparation. Protein LoBind microcentrifuge tubes and MS-grade reagents were used throughout MS sample preparation.

Enrichment, alkylation, and digest for photoaffinity labeling experiments. Per sample, $50 \mu \mathrm{L}$ avidin slurry (Sigma) was dispensed into a microcentrifuge tube and washed $3 \times$ with $0.2 \%$ (w/v) SDS/PBS (3 min, $400 \times g$ ). Protein samples were centrifuged $(21000 \times \mathrm{g}, 10 \mathrm{~min}, \mathrm{RT})$ to remove particulates, then added to the beads, and incubated at RT under constant rotation for 1-2 h. Beads were pelleted, the supernatant discarded, and beads were washed with $0.5-1 \mathrm{~mL}$ of the following solutions: $2 \times 1 \%$ $(\mathrm{w} / \mathrm{v})$ SDS/PBS, then $3 \times 4 \mathrm{M}$ urea/PBS, and $3 \times 50 \mathrm{mM}$ triethylammonium bicarbonate buffer (TEAB). The beads were resuspended in $100 \mu \mathrm{L} 50 \mathrm{mM}$ TEAB and reduced with $10 \mathrm{mM}$ DTT (from $250 \mathrm{mM}$ stock in water) at $55^{\circ} \mathrm{C}$ for 30 min with shaking. Next, beads were washed with $0.5 \mathrm{~mL}$ TEAB, resuspended in $100 \mu \mathrm{L}$ TEAB and thiols were 
alkylated with $20 \mathrm{mM}$ iodoacetamide (from $500 \mathrm{mM}$ stock in TEAB) at $25^{\circ} \mathrm{C}$ from 30 min with shaking. Beads were washed twice with $100 \mu \mathrm{L}$ TEAB, resuspended in $100 \mu \mathrm{L}$ $\mathrm{TEAB}$, and $1 \mu \mathrm{g}$ trypsin was added (from $0.5 \mu \mathrm{g} / \mu \mathrm{L}$ in $50 \mathrm{mM}$ acetic acid, Promega). Proteins were digested at $37^{\circ} \mathrm{C}$ for $14 \mathrm{~h}$ under vigorous shaking. The digest was quenched with formic acid $(1 \%(\mathrm{v} / \mathrm{v})$ final concentration, $\mathrm{pH} 2-3)$, beads were washed twice with $100 \mu \mathrm{L} 0.1 \%(\mathrm{v} / \mathrm{v})$ formic acid, and the washes were combined with the supernatant.

Desalting on stage tip for photoaffinity labeling experiments. Stage tips consisted of three layers of C-18 material (Empore C18 disk-C18, $47 \mathrm{~mm}$, Agilent Technologies) plunged into p200 tips and were inserted into holes in the lids of microcentrifuge tubes. The following solutions were added, and the stage tips were centrifuged ( $\leq 1-2 \mathrm{~min}, 500 \times \mathrm{g}$ ) after every addition: stage tips were washed with $1 \times 80 \mu \mathrm{L}$ methanol and then equilibrated with $1 \times 80 \mu \mathrm{L} 80 \%(\mathrm{v} / \mathrm{v})$ acetonitrile, $0.5 \%(\mathrm{v} / \mathrm{v})$ formic acid and with $2 \times 100 \mu \mathrm{L} 0.5 \%(\mathrm{v} / \mathrm{v})$ formic acid. Next, peptides were loaded and desalted with $1 \times 150 \mu \mathrm{L} 0.1 \%(\mathrm{v} / \mathrm{v})$ formic acid. Stage tips were transferred to fresh LoBind microcentrifuge tubes and the peptides were eluted with $100 \mu \mathrm{L} 80 \%(\mathrm{v} / \mathrm{v})$ acetonitrile, $0.5 \%(\mathrm{v} / \mathrm{v})$ formic acid. Solvents were removed in a speed vac and dry peptides were stored at $-80^{\circ} \mathrm{C}$ until analysis.

Chemoproteomic experiments with isoDTB tags. A pellet of $V$. campbellii grown to stationary phase $\left(\mathrm{OD}_{600} \sim 5.0, \sim 24\right.$ $\mathrm{mL}$ ) was washed $3 \times$ with PBS, stored at $-80{ }^{\circ} \mathrm{C}$ before lysis in $1.5 \mathrm{~mL}$ PBS with sonication $(5 \times 15 \mathrm{~s}, 60 \%$ intensity, on ice), and insoluble proteins were removed by centrifugation $\left(16,060 \times g, 30 \mathrm{~min}, 4^{\circ} \mathrm{C}\right)$. Protein concentration was adjusted to $1 \mathrm{mg} / \mathrm{mL}$, and $2 \mathrm{~mL}$ lysate was labeled with $10 \mu \mathrm{M}$ PE-P $(2 \mu \mathrm{L}$ of a $10 \mathrm{mM}$ stock in DMSO) at $30^{\circ} \mathrm{C}$ for $1 \mathrm{~h}, 200 \mathrm{rpm}$. Following $10 \mathrm{~min}$ UVirradiation (UV low-pressure mercury-vapor fluorescent lamp, Philips TL-D 18W BLB, $360 \mathrm{~nm}$ maximum) in a 6-well plate (Thermo Scientific), the lysate was split into $2 \times 800 \mu \mathrm{L}$ and adjusted to $1 \%(\mathrm{w} / \mathrm{v})$ SDS (from a $10 \%(\mathrm{w} / \mathrm{v})$ stock in PBS) before adding the Click reagents as for the photoaffinity labeling experiments except using either heavy or light labeled isoDTB azide $(100 \mu \mathrm{M}$ final from a $5 \mathrm{mM}$ DMSO stock, isoDTB azide synthesized as reported previously (39)). After the Click reaction, heavy- and lightlabeled lysates $(800 \mu \mathrm{L}$ each) were combined in $8 \mathrm{~mL}$ cold acetone and precipitated overnight at $-20^{\circ} \mathrm{C}$. Precipitated proteins were centrifuged $\left(10,178 \times g, 10 \mathrm{~min}, 4^{\circ} \mathrm{C}\right)$, the supernatant decanted, the pellet resuspended in $1 \mathrm{~mL}$ cold methanol with sonication ( $10 \%$ intensity), and pelleted again $\left(13,000 \times g, 10 \mathrm{~min}, 4^{\circ} \mathrm{C}\right)$. The methanol wash was repeated, and protein pellets were air-dried and resuspended in $300 \mu \mathrm{L} 8 \mathrm{M}$ urea in $0.1 \mathrm{M}$ TEAB with sonication $(10 \%$ intensity). Samples were centrifuged $(16,249 \times \mathrm{g}, 3 \mathrm{~min})$ and reduced with $10 \mathrm{mM}$ DTT $(15 \mu \mathrm{L}$ of $201 \mathrm{mM}$ stock in water) for $45 \mathrm{~min}$ at $37^{\circ} \mathrm{C}, 850 \mathrm{rpm}$. Next, thiols were alkylated with $20 \mathrm{mM}$ iodoacetamide $(15 \mu \mathrm{l}$ from a $400 \mathrm{mM}$ stock in water) for $30 \mathrm{~min}$ at $25^{\circ} \mathrm{C}, 850 \mathrm{rpm}$ (protected from light) and remaining iodoacetamide was quenched with $10 \mathrm{mM}$ DTT for $30 \mathrm{~min}$ at $25^{\circ} \mathrm{C}, 850 \mathrm{rpm}$. Then, $900 \mu \mathrm{L} 0.1 \mathrm{M}$ TEAB was added (to $\mathrm{pH} \sim 8$ and $2 \mathrm{M}$ urea) and proteins were digested with $20 \mu \mathrm{g}$ trypsin $(40 \mu \mathrm{L}$ from $0.5 \mu \mathrm{g} / \mu \mathrm{L}$ in $50 \mathrm{mM}$ acetic acid, Promega) overnight at $37^{\circ} \mathrm{C}$ with intense shaking. Per sample, $2 \times 25 \mu \mathrm{L}$ avidin slurry (Sigma) in Protein LoBind tubes was washed with $3 x$ $1 \mathrm{~mL} 1 \%(\mathrm{v} / \mathrm{v}) \mathrm{NP}-40$ in PBS with centrifugation $(400 \times \mathrm{g}, 2$ min). The tryptic digest was split into two portions, added to $600 \mu \mathrm{L} 0.2 \%(\mathrm{v} / \mathrm{v}) \mathrm{NP}-40$ and then to the avidin beads and incubated for $2.5 \mathrm{~h}$ with constant rotation. Beads were then centrifuged (1,000 × $g, 2 \mathrm{~min})$, the supernatant discarded, and the beads were resuspended in $600 \mu \mathrm{L} 0.1 \%(\mathrm{v} / \mathrm{v}) \mathrm{NP}$ 40, and transferred to a centrifuge column (Fisher Scientific) recombining the two portions of one sample. Beads were washed with $2 \times 600 \mu \mathrm{L} 0.1 \%(\mathrm{v} / \mathrm{v}) \mathrm{NP} 40$, then with $3 \times 600$ $\mu \mathrm{L}$ PBS, and with $3 \times 600 \mu \mathrm{L}$ water, after every washing step the solutions were removed by suction. The columns were transferred into LoBind tubes and peptides were eluted with $400 \mu \mathrm{L}$ (in 3 batches) $50 \%(\mathrm{v} / \mathrm{v})$ acetonitrile, $0.1 \%(\mathrm{v} / \mathrm{v})$ formic acid in water with centrifugation (5,000 $\times$ g, $3 \mathrm{~min})$. Solvents were removed in a speed vac and dry peptides were stored at $-80^{\circ} \mathrm{C}$ until analysis.

Co-IP. For details on Co-IP experimental procedures and antibody generation see SI Appendix, supplementary methods.

Peptide reconstitution (all proteomics experiments). Dry peptides were reconstituted in $30 \mu \mathrm{L} 1 \%(\mathrm{v} / \mathrm{v})$ formic acid with vortexing and in a sonication bath (10 $\mathrm{min})$ and filtered through centrifugal filters $(0.22 \mu \mathrm{m}$, Durapore, PVDF, Merck $K G a A)$ pre-equilibrated with $300 \mu \mathrm{L} 1 \%(\mathrm{v} / \mathrm{v})$ formic acid $(16,249 \times \mathrm{g}, 2 \mathrm{~min}, \mathrm{RT})$. For details on MS instrument settings and MS data analysis, see SI Appendix.

Plasmid construction and protein purification. For a detailed description of the construction of the $V$. campbellii $\Delta$ cheW knockout strain, the plasmid coding for $\mathrm{N}$-terminally His6-tagged CheW, and CheW purification see SI Appendix, supplementary methods, Table S4 - S5.

Microscale thermophoresis. PD-10 desalting columns packed with Sephadex G-25 resin (GE Healthcare) were used to exchange $6 \mathrm{His}-\mathrm{CheW}$ protein buffer to MST buffer (PBS with $0.05 \%$ (v/v) Tween 20). Purified CheW was labeled using the RED-tris-NTA Labeling kit (NanoTemper Technologies) according to the manufacturer's instructions. Ligands were dissolved in MST buffer and serially diluted. For thermophoresis, a constant concentration of fluorescently labeled $6 \mathrm{His}-\mathrm{CheW}(100 \mathrm{nM})$ was mixed with increasing ligand concentrations, resulting in a final concentration of $50 \mathrm{nM}$ labeled $6 \mathrm{His}-\mathrm{CheW}$ and final ligand concentrations in a range of $7.63 \mathrm{~nm}-500 \mu \mathrm{M}$. After $10 \mathrm{~min}$ incubation at RT, followed by centrifugation $(10,000 \times \mathrm{g}, 10$ $\min$ ) to remove aggregates, the solution was soaked into 
Monolith NT. 115 Series Standard Treated Capillaries. MST measurements were carried out using a Monolith NT.115 instrument (NanoTemper Technologies) with 60\% LED/ excitation power and medium MST power (40\%). Three independent measurements were analyzed (NT Analysis software version 1.5.41, NanoTemper Technologies) using the signal from Thermophoresis + T-Jump.

3D motility assay. $20 \mu \mathrm{L}$ bacterial culture was added to 1 $\mathrm{mL}$ TMN containing EPI at the specified concentration, mixed gently, and left on the bench for $30 \mathrm{~min}$. The solutions were then flowed into sample chambers, consisting of three layers of parafilm as spacers between a microscopy slide and a \#1 coverslip that had been heated and pressed to seal. After filling, the ends of the filled chamber were sealed with molten valap (a mixture of vaseline, lanolin, and paraffin) and immediately brought to the microscope for recording, all within 60 min of dilution from the day culture. EPI was diluted into TMN from a $50 \mathrm{mM}$ stock solution in DMSO stored at $-20^{\circ} \mathrm{C}$, within $3 \mathrm{~h}$ before the experiment.

3D chemotaxis assays. Cells were prepared as for 3D motility assays. For glucose chemotaxis experiments, glucose was omitted in the motility medium TMN. 3D chemotaxis experiments were performed using a highthroughput chemotaxis assay (47) using a commercially available microfluidic device (Ibidi) consisting of two $65 \mu \mathrm{L}$ reservoirs connected by a $1 \mathrm{~mm}$-long channel with a height of $70 \mu \mathrm{m}$ and a width of $1 \mathrm{~mm}$. V. campbellii cultures were diluted into chemotaxis buffer without (creating solution $A$ ) or with the putative chemoattractant (creating solution B) to a target $\mathrm{OD}_{600}$ of 0.008 for EPI gradients or $\mathrm{OD}_{600} 0.005$ for serine and glucose gradients. Chemotaxis buffer consisted of TMN, with an added background of EPI or PE for some experiments as specified, and without glucose for glucose gradients. Chemoattractants included EPI, L-serine, and Dglucose at the specified concentrations. First, the entire microfluidic device was overfilled with solution $A$. Then, the content of one reservoir was exchanged by solution B. A linear chemical gradient was established in the narrow channel between reservoirs within approximately $30 \mathrm{~min}$ and stable for several hours. About 40-60 min after closing the device, 3D bacterial trajectories were acquired in the middle of this gradient. For experiments with EPI gradients, EPI was prepared as a $40 \mathrm{mM}$ stock in TMN within $3 \mathrm{~h}$ before the experiment. For serine chemotaxis experiments, EPI was prepared as $20 \mathrm{mM}$ stock in TMN within $3 \mathrm{~h}$ before the experiments. For glucose chemotaxis experiments, EPI and PE were prepared as $60 \mathrm{mM}$ stock in water, within $3 \mathrm{~h}$ before the experiment. For data acquisition and analysis of 3D trajectories see SI Appendix.

Chemotaxis capillary assay. The capillary assay was performed following a published protocol (48) adapted for Vibrio species $(55,56)$. Briefly, V. campbellii overnight cultures were diluted into LB35 medium (1:100) and grown to $\mathrm{OD}_{600} 0.5$. The cells were gently washed three times (10 min, 2,000 $\times$ g) and resuspended in HEPES-buffered artificial seawater (H-ASW: $100 \mathrm{mM} \mathrm{MgSO}_{4}, 20 \mathrm{mM} \mathrm{CaCl}_{2}$, $20 \mathrm{mM} \mathrm{KCl}, 400 \mathrm{mM} \mathrm{NaCl}$, and $50 \mathrm{mM}$ HEPES, pH 7.5) (57). The $\mathrm{OD}_{600}$ was adjusted to 0.1 , and $200 \mu \mathrm{L}$ culture was transferred into a 96-well plate. The plate was covered with three layers of parafilm and the open end of a flame-sealed $1 \mu \mathrm{L}$ capillary (64 mm, Drummond Scientific) was inserted into the bacterial suspension. The capillaries were filled with either $\mathrm{H}$-ASW alone or with attractants dissolved in $\mathrm{H}-\mathrm{ASW}$. Solutions containing attractants and cell suspensions were supplemented with catecholamines and antagonists as indicated. The hormones were either dissolved in $\mathrm{H}-\mathrm{ASW}$ or diluted from a 100 -fold concentrated stock solution in $0.1 \mathrm{M}$ $\mathrm{HCl}$ prepared immediately before the experiment (EPI and NE) and added directly after the wash steps. After $60 \mathrm{~min}$ incubation at room temperature, the contents of the capillaries were expelled and plated in appropriate dilutions on LB agar plates containing carbenicillin. The plates were incubated at $30^{\circ} \mathrm{C}$ overnight and colony forming units were enumerated. Each experiment was conducted at least three times with four technical replicates per condition. Statistical significance was determined using a one-way ANOVA analysis $\left({ }^{*}=p<0.05,{ }^{* *}=p<0.01\right)$.

\section{Acknowledgments}

A.W.M. was supported by the Studienstiftung des Deutschen Volkes. S.M.H. acknowledges funding by the Fonds der Chemischen Industrie through a Liebig Fellowship and by the TUM Junior Fellow Fund. S.A.S. acknowledges funding from the European Research Council (ERC) and the European Union's Horizon 2020 research and innovation program (grant agreement No 725085, CHEMMINE, ERC consolidator grant) as well as from the Helmholtz Institute for Pharmaceutical Research Saarland (HIPS). M.G. and K.M.T. were supported by the Rowland Institute at Harvard. K.J. acknowledges funding from the Deutsche Forschungsgemeinschaft, project number 395357507-SFB1371. We thank Prof. Simon Ringgaard for help with the capillary assay, Mona Wolff and Katja Bäuml for technical support, Juanita Ferreira Olmos for synthetic assistance, and Dr. Isabel Wilkinson for critical reading of this manuscript.

\section{Data deposition}

The mass spectrometry proteomics data have been deposited to the ProteomeXchange Consortium via the PRIDE partner repository (58) with the dataset identifier PXD029119. 


\section{Author Contributions:}

A.W.M., E.H., K.S., K.M.T., and M.G. performed research; A.W.M., E.H., K.S., M.G., and S.M.H. analyzed data; K.M.T, S.A.S., and K.J. designed research; A.W.M., S.A.S., and K.J. wrote the manuscript with input from all authors.

Competing Interest Statement: The authors declare no competing financial interest.

\section{References}

1. P. P. Freestone et al., Growth stimulation of intestinal commensal Escherichia coli by catecholamines: a possible contributory factor in trauma-induced sepsis. Shock (Augusta, Ga.) 18, 465-470 (2002).

2. P. P. Freestone et al., The mammalian neuroendocrine hormone norepinephrine supplies iron for bacterial growth in the presence of transferrin or lactoferrin. J. Bacteriol. 182, 60916098 (2000).

3. B. L. Bearson, S. M. Bearson, The role of the QseC quorum-sensing sensor kinase in colonization and norepinephrine-enhanced motility of Salmonella enterica serovar Typhimurium. Microb. Pathog. 44, 271-278 (2008).

4. P. Halang et al., Response of Vibrio cholerae to the catecholamine hormones epinephrine and norepinephrine. J. Bacteriol. 197, 3769-3778 (2015).

5. Q. Yang, N. D. Q. Anh, P. Bossier, T. Defoirdt, Norepinephrine and dopamine increase motility, biofilm formation, and virulence of Vibrio harveyi. Front. Microbiol. 5, 1-12 (2014).

6. V. Sperandio, A. G. Torres, B. Jarvis, J. P. Nataro, J. B. Kaper, Bacteria-host communication: The language of hormones. Proc. Natl. Acad. Sci. U.S.A. 100, 8951-8956 (2003).

7. M. Merighi et al., Genome-wide analysis of the PreA/PreB (QseB/QseC) regulon of Salmonella enterica serovar Typhimurium. BMC Microbiol. 9, 42-42 (2009).

8. C. G. Moreira, D. Weinshenker, V. Sperandio, QseC mediates Salmonella enterica serovar Typhimurium virulence in vitro and in vivo. Infect. and Immun. 78, 914-926 (2010).

9. P. Freestone, Communication between bacteria and their hosts. Scientifica 2013, 361073-361087 (2013).

10. N. C. Reading, D. A. Rasko, A. G. Torres, V. Sperandio, The two-component system QseEF and the membrane protein QseG link adrenergic and stress sensing to bacterial pathogenesis. Proc. Natl. Acad. Sci. U.S.A. 106, 5889-5894 (2009).

11. M. B. Clarke, D. T. Hughes, C. Zhu, E. C. Boedeker, V. Sperandio, The QseC sensor kinase: A bacterial adrenergic receptor. Proc. Natl. Acad. Sci. U.S.A. 103, 10420-10425 (2006).

12. G. D. Pullinger et al., Norepinephrine augments Salmonella enterica-induced enteritis in a manner associated with increased net replication but independent of the putative adrenergic sensor kinases QseC and QseE. Infect. Immun. 78, 372380 (2010).

13. T. Bansal et al., Differential effects of epinephrine, norepinephrine, and indole on Escherichia coli O157:H7 chemotaxis, colonization, and gene expression. Infect Immun 75, 4597-4607 (2007).

14. N. Sule et al., The norepinephrine metabolite 3,4dihydroxymandelic acid is produced by the commensal microbiota and promotes chemotaxis and virulence gene expression in enterohemorrhagic Escherichia coli. Infect. Immun. 85, e00431-00448 (2017).

15. S. Pasupuleti et al., Chemotaxis of Escherichia coli to norepinephrine (NE) requires conversion of $\mathrm{NE}$ to 3,4-dihydroxymandelic acid. J. Bacteriol. 196, 39924000 (2014).

16. S. Bi, V. Sourjik, Stimulus sensing and signal processing in bacterial chemotaxis. Curr. Opin. Microbiol. 45, 22-29 (2018).

17. J. G. Lopes, V. Sourjik, Chemotaxis of Escherichia coli to major hormones and polyamines present in human gut. ISME J. 12, 2736-2747 (2018).

18. B. Lin et al., Comparative genomic analyses identify the Vibrio harveyi genome sequenced strains BAA1116 and HY01 as Vibrio campbellii. Environ. Microbiol. Rep. 2, 81-89 (2010).

19. B. L. Bassler, M. Wright, R. E. Showalter, M. R. Silverman, Intercellular signalling in Vibrio harveyi: sequence and function of genes regulating expression of luminescence. Mol. Microbiol. 9, 773786 (1993).

20. K. Papenfort, B. L. Bassler, Quorum sensing signalresponse systems in Gram-negative bacteria. Nat. Rev. Microbiol. 14, 576-588 (2016).

21. C. Anetzberger et al., Autoinducers act as biological timers in Vibrio harveyi. PLoS One 7, e48310e48310 (2012).

22. B. Austin, X.-H. Zhang, Vibrio harveyi: a significant pathogen of marine vertebrates and invertebrates. Lett. Appl. Microbiol. 43, 119-124 (2006).

23. K. M. Ottemann, J. F. Miller, Roles for motility in bacterial-host interactions. Mol. Microbiol. 24, 11091117 (1997). 
24. S. M. Sandrini et al., Elucidation of the mechanism by which catecholamine stress hormones liberate iron from the innate immune defense proteins transferrin and lactoferrin. J. Bacteriol. 192, 587-594 (2010).

25. C. Toulouse et al., Mechanism and impact of catecholamine conversion by Vibrio cholerae. Biochim. Biophys. Acta Bioenerg. 1860, 478-487 (2019).

26. M. Fonović, M. Bogyo, Activity-based probes as a tool for functional proteomic analysis of proteases. Expert Rev. Proteom. 5, 721-730 (2008).

27. M. J. Evans, B. F. Cravatt, Mechanism-based profiling of enzyme families. Chem. Rev. 106, 32793301 (2006).

28. M. H. Wright, S. A. Sieber, Chemical proteomics approaches for identifying the cellular targets of natural products. Nat. Prod. Rep. 33, 681-708 (2016).

29. Z. Li et al., Design and synthesis of minimalist terminal alkyne-containing diazirine photocrosslinkers and their incorporation into kinase inhibitors for cell- and tissue-based proteome profiling. Angew. Chem. Int. Ed. 52, 8551-8556 (2013).

30. E. Monzani et al., Dopamine, oxidative stress and protein-quinone modifications in Parkinson's and other neurodegenerative diseases. Angew. Chem. Int. Ed. 58, 6512-6527 (2019).

31. M. Marchetti et al., Iron metabolism at the interface between host and pathogen: from nutritional immunity to antibacterial development. Int. J. Mol. Sci. 21, 2145-2188 (2020).

32. K. S. Kinney, C. E. Austin, D. S. Morton, G. Sonnenfeld, Norepinephrine as a growth stimulating factor in bacteria--mechanistic studies. Life Sci. 67, 3075-3085 (2000).

33. A. Khan, P. Singh, A. Srivastava, Synthesis, nature and utility of universal iron chelator - Siderophore: A review. Microbiol. Res. 212-213, 103-111 (2018).

34. S. Sandrini, M. Aldriwesh, M. Alruways, P. Freestone, Microbial endocrinology: host-bacteria communication within the gut microbiome. J. Endocrinol. 225, R21-34 (2015).

35. J. Cox et al., Accurate proteome-wide label-free quantification by delayed normalization and maximal peptide ratio extraction, termed MaxLFQ. Mol. Cell. Proteomics 13, 2513-2526 (2014).

36. V. V. Rostovtsev, L. G. Green, V. V. Fokin, K. B. Sharpless, A stepwise Huisgen cycloaddition process: copper(I)-catalyzed regioselective "ligation" of azides and terminal alkynes. Angew. Chem. Int. Ed. 41, 2596-2599 (2002).
37. H. C. Kolb, M. G. Finn, K. B. Sharpless, Click chemistry: diverse chemical function from a few good reactions. Angew. Chem. Int. Ed. 40, 20042021 (2001).

38. J. Cox et al., Accurate proteome-wide label-free quantification by delayed normalization and maximal peptide ratio extraction, termed MaxLFQ. Mol. Cell. Proteomics 13, 2513-2526 (2014).

39. P. R. A. Zanon, L. Lewald, S. M. Hacker, Isotopically labeled desthiobiotin azide (isoDTB) tags enable global profiling of the bacterial cysteinome. Angew. Chem. Int. Ed. 59, 2829-2836 (2020).

40. P. W. A. Allihn, M. W. Hackl, C. Ludwig, S. M. Hacker, S. A. Sieber, A tailored phosphoaspartate probe unravels CprR as a response regulator in Pseudomonas aeruginosa interkingdom signaling. Chem. Sci. 12, 4763-4770 (2021).

41. P. R. A. Zanon et al., Profiling the proteome-wide selectivity of diverse electrophiles. ChemRxiv https://doi.org/10.26434/chemrxiv.14186561.v1 (2021).

42. C. J. Wienken, P. Baaske, U. Rothbauer, D. Braun, S. Duhr, Protein-binding assays in biological liquids using microscale thermophoresis. Nat. Commun. 1, 100-106 (2010).

43. A. Fux, V. S. Korotkov, M. Schneider, I. Antes, S. A. Sieber, Chemical cross-linking enables drafting ClpXP proximity maps and taking snapshots of in situ interaction networks. Cell Chem. Biol. 26, 4859.e47 (2019).

44. A. Briegel, M. Beeby, M. Thanbichler, G. J. Jensen, Activated chemoreceptor arrays remain intact and hexagonally packed. Mol. Microbiol. 82, 748-757 (2011).

45. L. Xie, T. Altindal, S. Chattopadhyay, X.-L. Wu, Bacterial flagellum as a propeller and as a rudder for efficient chemotaxis. Proc. Natl. Acad. Sci. U.S.A. 108, 2246-2251 (2011).

46. S. Ringgaard et al., ParP prevents dissociation of CheA from chemotactic signaling arrays and tethers them to a polar anchor. Proc. Natl. Acad. Sci. U.S.A. 111, E255-E264 (2014).

47. M. Grognot, K. M. Taute, A multiscale 3D chemotaxis assay reveals bacterial navigation mechanisms. Commun. Biol. 4, 669-676 (2021).

48. J. Adler, A method for measuring chemotaxis and use of the method to determine optimum conditions for chemotaxis by Escherichia coli. J. Gen. Microbiol. 74, 77-91 (1973).

49. R. P. Alexander, A. C. Lowenthal, R. M. Harshey, K. M. Ottemann, CheV: CheW-like coupling proteins at the core of the chemotaxis signaling network. Trends Microbiol. 18, 494-503 (2010). 
50. S. M. Butler, A. Camilli, Both chemotaxis and net motility greatly influence the infectivity of Vibrio cholerae. Proc. Natl. Acad. Sci. U.S.A. 101, 50185023 (2004).

51. S. M. Butler et al., Cholera stool bacteria repress chemotaxis to increase infectivity. Mol. Microbiol. 60, 417-426 (2006).

52. S. H. Lee, S. M. Butler, A. Camilli, Selection for in vivo regulators of bacterial virulence. Proc. Natl. Acad. Sci. U.S.A. 98, 6889-6894 (2001).

53. D. S. Merrell et al., Host-induced epidemic spread of the cholera bacterium. Nature 417, 642-645 (2002).

54. J. Eirich et al., Pretubulysin derived probes as novel tools for monitoring the microtubule network via activity-based protein profiling and fluorescence microscopy. Mol. Biosyst. 8, 2067-2075 (2012).

55. N. Sar, L. McCarter, M. Simon, M. Silverman, Chemotactic control of the two flagellar systems of Vibrio parahaemolyticus. J Bacteriol 172, 334-341 (1990).

56. C. A. Brennan, M. J. Mandel, M. C. Gyllborg, K. A. Thomasgard, E. G. Ruby, Genetic determinants of swimming motility in the squid light-organ symbiont Vibrio fischeri. MicrobiologyOpen 2, 576-594 (2013).

57. E. G. Ruby, K. H. Nealson, Symbiotic association of Photobacterium fisheri with the marine luminous fish Monocentris japonica: a model of symbiosis based on bacterial studies. Biol. Bull. 151, 574-586 (1976).

58. Y. Perez-Riverol et al., The PRIDE database and related tools and resources in 2019: improving support for quantification data. Nucleic Acids Res. 47, D442-D450 (2018). 